\title{
Research on the Application of "effective Preview" Teaching method based on Mobile Communication equipment in Organic Chemistry Teaching
}

\author{
Chen Ling, Fu Feie \\ College of Chemical Engineering, Yunnan National Defense Industry Vocational and Technical \\ College, Kunming, Yunnan 650500,Eail:327248439@qq.com
}

\begin{abstract}
Organic Chemistry is a basic core course in chemistry, biology and pharmacy. Characteristics of Organic Chemistry are wide coverage, various compounds, rich contents and complex chemical reactions ${ }^{[1][2]}$. Because of the poor basic and self-study ability of the students in higher vocational school, the teachers often feel the great effort in the teaching process with poor effect. The combination of preview and test in the teaching software named “Classroom assignment” can greatly improve the students' preview effect, In addition, it strengthen the students' self-study ability and the teachers' ability to manage the students' study, which greatly improve the teaching effect of organic chemistry.
\end{abstract}

Keywords: Organic Chemistry; classroom assignment; Preview; Test.

\section{Introduction}

Preview is an important link in the process of education. It can make students have a preliminary perception of the knowledge they are studying and prepare themselves for class ${ }^{[3]}$, so as to cultivate students' learning ability and improve the efficiency of attending classes.Because the Cognitive driving Power and Self-improvement of internal drive of Vocational College students' Preview motivation are poor , in order to improve the learning efficiency of them, we must take subordinate internal drive as the breakthrough.

However, at this stage, preview tends to be formalized, which is, which ending in the form of reading is invalid. In the final analysis, it is due to the low internal drive of the attached students, which can not stimulate the students' preparation motivation.

Effective preview is proposed as opposed to invalid preview, The effectiveness of preview refers to learning by students' initiative, conscientiously implement the knowledge point of the textbook and question the content, and make clear the purpose and significance of learning new knowledge.Through effective preparation, it can,improve the efficiency of listening to classes, and cultivate the ability of autonomous learning as will as stimulate students' interest in learning.

In view of the poor self-study ability of higher vocational students, they have not developed good learning habits.We decided to apply "effective preview method" to the "Organic Chemistry" teaching of 2017 drug production technology specialty, and compare it with the traditional teaching method of 2016 drug production technology specialty.Compare the teaching effect of "effective preview" method.

\section{2. "effective preview" implementation concept}

The teaching of organic chemistry in higher vocational colleges requires students to connect theory with practice and cultivate skilled talents. In the normal teaching link, the proportion of practical links is more serious.

In order to stimulate students' learning motivation and strengthen the subordinate drive of preview, we will increase the proportion of grades in peacetime, which consist of preview time, preview tests, classroom interaction, experimental design, operation in experiment.It can change the unfairness of "one test" and avoid some unfavorable learning conditions, such as the shock before the examination, and realize the concept of quality education.

At the same time, in order to comply with the requirements of teaching cooperation and education informatization , the study content and task are posted on the class APP in the smart phone ${ }^{[4]}$, which is the most commonly used mobile communication device. So that students can make full use of their leisure time to learn at anytime and anywhere. 


\section{3."effective preview" implementation plan and evaluation mechanism}

3.1 implementation: in Organic Chemistry teaching, we adopt the "Courseware Preview + Preview Test" preview method.

3.1.1 Courseware preview: the students send APP to read the courseware through the classroom on the mobile phone, which can question the content. Teachers can count more questions of students and focus on explaining them in class. At the same time, classroom assignments will record the time spent by each student in the preparation of courseware.

3.1.2 Preview test: after reading the courseware, the students need to complete the preview test (the subjects of the test are all from the courseware, with the objective questions as the main task), students can answer easily as long as they read the courseware carefully.After submitting the test , you can refer to your preview test results . If you are not satisfied with the results, you can apply for the teacher to play back .

3.2 evaluation mechanism: the preview effect is appraise from the preview time, preview results and classroom interaction ${ }^{[5][6]}$ which is the interaction added in PPT knowledge.(It can strengthen the classroom management through interaction, and testing Knowledge acquisition).Students can test self assessment from the correct rate of preview test and strengthen the reflective ability.

\section{4. "effective preview" data statistics}

We easily get the following data by APP

4.1 Preview time: the average preparation time for each PPT session is as follows:

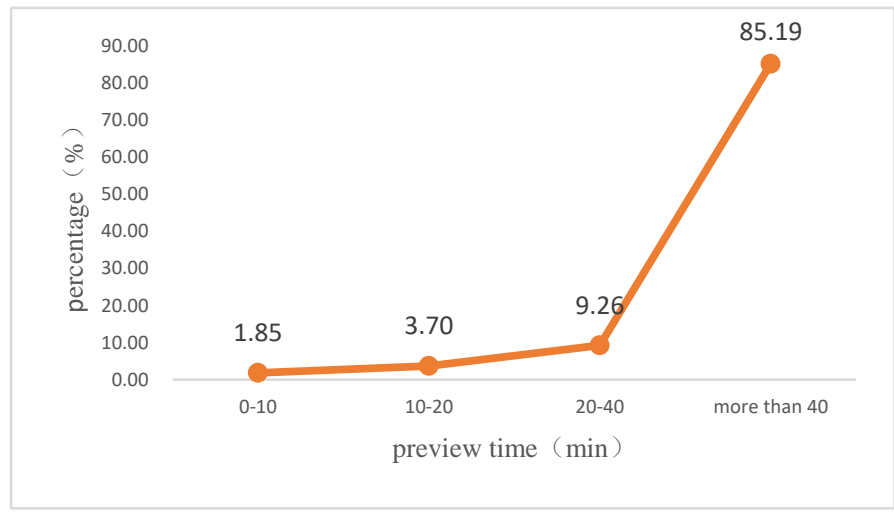

Figure 1: preview time distribution

4.2 preparation test, classroom interaction score:

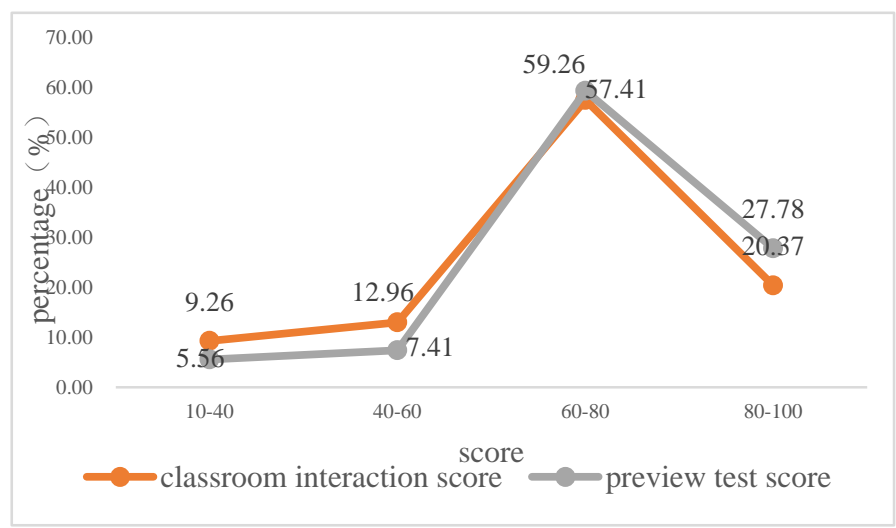

Figure 2: preview test, classroom interaction score distribution

\section{Analysis of the result of "effective preview"}

5.1 classroom performance: in the theory class, most students can keep up with the teacher's teaching rhythm, the classroom atmosphere is better, which can speed up the teaching progress appropriately.Those who have more than 40 minutes of preparation time and 80 or more test scores in the experimental class can understand the 
principle and complete the experiment on their own.If the test score is between 60 and 80 points, the test can be completed successfully by the teacher. If it is less than 60 points, they can complete the experiment only through the guidance of the teacher.

5.2 final results statistics:

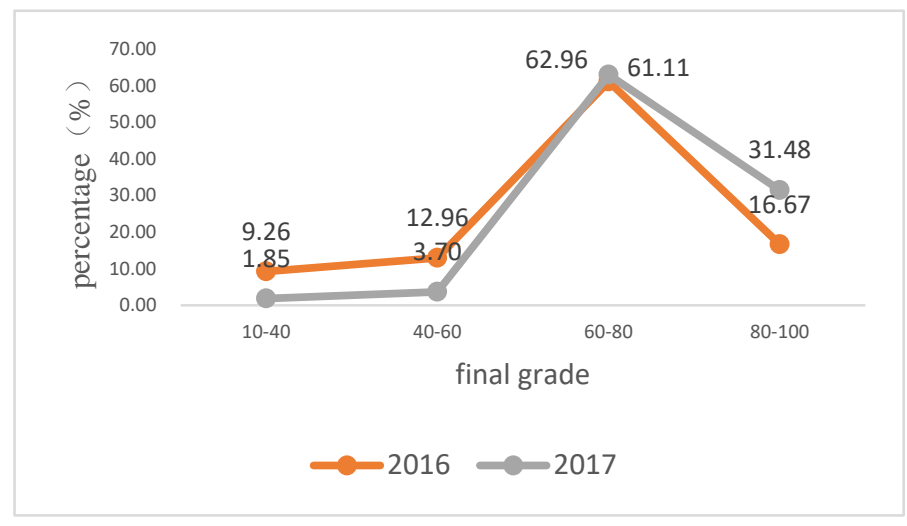

Figure 3: final grades for class 2016 and 2017

The pass rate of students in class 2017 increased by 16.66 and that of students above 80 increased by 14.81 .. 5.3 Student satisfaction statistics

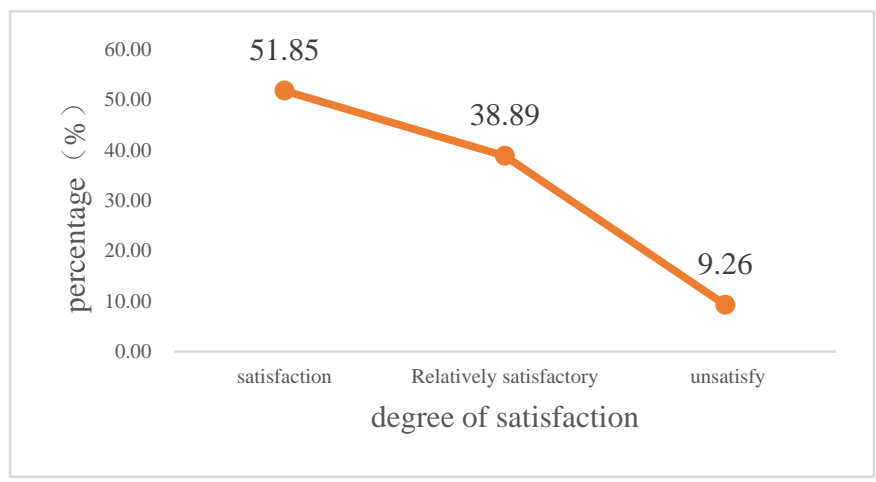

Figure 4: student satisfaction questionnaire

Through the survey, 9.26\% of the students thought that the method had more homework and felt that the pressure of study was too great to accept it.

\section{Conclusion}

effective preview not only improves the efficiency of listening to classes, cultivates the innovative consciousness, but also enhances the students' learning ability and self-confidence, and the teaching effect is also improved.But the preparation program depends on the student's learning ability and foundation.

\section{Acknowledgments}

The authors gratefully acknowledged the financial support by the research foundation of Yunnan Open University(2017-13)

\section{References}

[1] Liu Hongjie.A probe into the Teaching Reform of Organic Chemistry in Independent Colleges [J].Guangdong Chemical Industry, vol. 43, No. 2, January 2015, No. 208-209.

[2]Wang Jing, Wang Guangzhu.Discussion on the Project Teaching Reform of Organic Chemistry course for Pharmaceutical Specialty in higher Vocational Education[J], Guangdong Chemical Industry, No. 24, 2014, vol. 41, 
No. 151.

[3]Chen Yu, Li Caifang., Application of PBL Teaching method in Organic Chemistry Teaching in higher Vocational Education [J].Science and Technology Education No. 29,2014,141-143.

[4]Wang Yinglei.Research and consideration on Organic Chemistry Teaching in Applied undergraduate Colleges based on MOOC [J], Jiangxi Chemical Industry, No. 3, 2016, 176-178.

[5] Ge Shan.A brief talk on "rotation classroom" and Organic Chemistry Teaching in University [J].Science and technology horizon ,181.

[6]Zhang Baohai .Application of Interactive Teaching method in Organic Chemistry Teaching[J].Contemporary chemical research,May 2016,51-52. 